\title{
Central corneal thickness changes following manual small incision cataract surgery
}

This article was published in the following Dove Press journal:

Clinical Ophthalmology

20 January 2015

Number of times this article has been viewed

\author{
Olufisayo Temitayo Aribaba' \\ Olusesan Adetunji \\ Adenekan' \\ Adeola Olukorede \\ Onakoya' \\ Adekunle Rotimi-Samuel' \\ John Olutola Olatosi \\ Kareem Olatunbosun Musa' \\ Akinyele Oyedele Oyefeso' \\ Folashade Bolanle Akinsola' \\ 'Guinness Eye Centre, Lagos \\ University Teaching Hospital, \\ ${ }^{2}$ Department of Anaesthesia, College \\ of Medicine, University of Lagos, \\ Lagos, Nigeria
}

Correspondence: Olusesan Adetunji

Adenekan

Guinness Eye Centre, Lagos University

Teaching Hospital, Idi-Araba, Surulere,

PMB I2003, Lagos, Nigeria

Tel +2348033350540

Email tnelkon@yahoo.com

\begin{abstract}
Aim: To determine changes in post-cataract surgery central corneal thickness (CCT) at Lagos University Teaching Hospital by assessing the time it takes for the cornea to return to its preoperative thickness value.

Methods: This study is a prospective, hospital-based open within-patient controlled study with the unoperated eye controlling for the operated one.

Results: Two hundred patients with 400 eyes were analyzed, with bilateral mature cataract in $47.0 \%$. All the patients had manual small incision cataract surgery with posterior chamber intraocular lens implant. There is an increase in mean baseline CCT from $520.6 \pm 20.3 \mu \mathrm{m}$ by $76.9 \mu \mathrm{m}(597.9 \pm 30.4 \mu \mathrm{m}) 24$ hours after cataract surgery followed by relative reduction in the mean CCT to $555.2 \pm 24.7 \mu \mathrm{m}$ and $525.1 \pm 19.7 \mu \mathrm{m}$ at 2 weeks and 12 weeks, respectively. Increase in mean CCT in the unoperated and contralateral eyes were recorded in this study.

Conclusion: There was a transient increase in corneal thickness following cataract surgery with subsequent decrease to preoperative thickness by 12th and fourth week in the operated and unoperated eyes, respectively. Corneal manipulations during cataract surgery must be minimal to reduce visual rehabilitation time to barest minimum. Postoperative refraction will be better at eighth week to 12 th week considering the time it takes for the CCT to return to its stable preoperative values.
\end{abstract}

Keywords: post-cataract surgery visual rehabilitation, pachymetry, recovery time, unoperated eye

\section{Introduction}

Cataract is the leading cause of blindness in the world with blindness from cataract being particularly common in low-income countries. There are 39 million people reported to be blind worldwide. ${ }^{1}$ Age-related cataract is responsible for $51 \%$ of world blindness, which represents about 20 million people. ${ }^{2}$ According to the national blindness survey conducted in Nigeria in 2005-2007, out of the 25,061,000 adults above the age of 40 years, cataract was responsible for $42.9 \%$ magnitude of blindness. ${ }^{3}$

The corneal endothelium plays an important role in maintaining corneal transparency. The numerical density of corneal endothelium is highest at birth $(3,000$ cells/ $\mathrm{mm}^{2}$ ) and declines slowly but steadily thereafter. ${ }^{4}$ A minimal numerical density of $400-500$ cells $/ \mathrm{mm}^{2}$ is required to sustain the pumping activity of the endothelium. The cells of the endothelium do not regenerate, but they stretch to compensate for dead cells which reduce the overall cell density of the endothelium with consequent impact on fluid regulation. If the endothelium can no longer maintain a proper fluid balance, stromal swelling will occur, leading to loss of transparency with resultant impaired vision. Previous studies have shown that intraocular surgeries like cataract extraction affect corneal endothelial density. Interest has therefore developed in the assessment 
of endothelial damage either by cell counts or indirectly by measuring corneal thickness postoperatively. Many studies have been conducted in more developed settings among diverse races to determine how long it takes for the cornea to return to its preoperative thickness value after cataract surgery. This, therefore, leaves some uncertainties as to whether the findings from these studies apply to the African population. This study, therefore, aimed to determine changes in central corneal thickness (CCT) in patients after cataract surgery at Lagos University Teaching Hospital (LUTH) and to assess the length of time it takes for the cornea to return to its preoperative thickness value.

\section{Methods and materials}

This is a prospective, hospital-based open within-patient controlled study carried out in the ophthalmology clinic in LUTH between November 2012 and July 2013.

The sample size of 160 subjects for the study was determined using the statistical formula by Schlesselman. ${ }^{5}$ While making provision for attrition rate of $20 \%$, a total number of 192 approximated to 200 participants (400 eyes) were selected by consecutive sampling method. This was made up of 200 eyes that had cataract surgeries (cases) and 200 contralateral eyes that did not undergo cataract surgeries (controls).

Consecutive patients aged 18 years and above enrolled for small incision cataract surgery (SICS) with intraocular lens implantation performed by the same surgeon (OTA) formed the study patients. All the consenting patients underwent dilatation with topical Gutt tropicamide and phenylephrine and were prepped with 5\% povidone iodine solutions. All manual SICSs as described previously by Venkatesh et $\mathrm{al}^{6,7}$ were done under local anesthesia (peribulbar, retrobulbar, and rarely topical). After a limited conjunctival peritomy and light wetfield cautery, superior self-sealing sclerocorneal tunnel incision of 6.0-7.0 mm was created with a crescent blade, starting 1.5-2.0 mm behind the limbus. This incision was widened to approximately $9.0 \mathrm{~mm}$ as it advanced into the clear cornea. A large capsulorrhexis or rarely can-opening capsulotomy (6.0-7.0 mm) was performed with a cystotome followed by hydrodissection. A $3.0 \mathrm{~mm}$ keratome blade was used to open the internal lip of the tunnel incision. The nucleus was prolapsed into the anterior chamber using a Sinskey hook and extracted in one piece using the viscoelastic or the irrigating Simcoe cannula at the mouth of the tunnel incision. Cortical cleanup was performed with the Simcoe irrigatingaspirating cannula using Ringer's lactate or $0.9 \%$ normal saline solution. After implantation of a $6.00 \mathrm{~mm}$ diameter optic poly(methylmethacrylate) posterior chamber intraocular lens into the capsular bag, the side port was hydrated, and the anterior chamber was pressurized with the wound integrity intact and left unsutured in most cases.

Excluded from the study were patients with corneal opacity and endothelial defect such as leukoma, staphyloma, dystrophy, or corneal guttata, those with any preexisting ocular disease other than cataract, and those with traumatic or complicated cataract. Other excluded patients were those who have had refractive surgeries, those with only one eye, those with operative complications such as vitreous loss, and those who declined participation in the study.

The study was performed in accordance with the guidelines of the Declaration of Helsinki. Ethical approval was obtained from the hospital's Health Research and Ethics Committee. Structured questionnaires were administered to eligible and consenting patients by the authors after detailed explanation of the study and the procedures. They were also informed of the few possible side effects that can occur during examination such as peppery sensation from application of anesthetic eye drops. Relevant data obtained include the following: the biodata; eye to be operated; CCT measurements a day before cataract surgery; and CCT measurements a day after surgery, and at 2 weeks, 4 weeks, 8 weeks, and 12 weeks after surgery.

Corneal thickness measurements were done by one of the authors (OAA) on each participant using the ultrasonic SUOER ophthalmic A Scan Pachymeter SW 100 (model number GI 090760982 SN/0037CP) in the mornings of every visit. For each eye, the mean (SD) value of three measurements was calculated and recorded.

Data entry and analysis were done using Statistical Package for Social Sciences SPSS version 18. Frequencies, means, and standard deviations were generated to observe pattern of variable distribution among respondents. Comparison was done using the variable means of CCT using paired $t$-test and Pearson correlation. The time series analysis was also done. The analysis was considered to show statistically significant association when the $P$-value is $<0.05$.

\section{Results}

A total of 200 consecutive consenting patients with 400 eyes were analyzed in this study. Only $12(6.0 \%)$ of the patients were below 50 years, while $141(70.5 \%)$ were between the ages of 50 years and 69 years. Most of the patients were males, 118 (59.0\%). Over half of the participants, 116 (58.0\%), were Christians. The largest proportion, 157 (78.5\%), were of the Yoruba tribe (Table 1). 
Table I Demographic characteristics of respondents

\begin{tabular}{lll}
\hline Variable & Frequency $(\mathbf{n}=\mathbf{2 0 0})$ & Percent $\mathbf{( \% )}$ \\
\hline Age, years & 10 & 5.0 \\
$<40$ & 2 & 1.0 \\
$40-49$ & 46 & 23.0 \\
$50-59$ & 95 & 47.5 \\
$60-69$ & 47 & 23.5 \\
70 and above & & \\
Mean 63.3 \pm 8.5 & & \\
Sex & 118 & 59.0 \\
Male & 82 & 41.0 \\
Female & & \\
Religion & 116 & 58.0 \\
Christianity & 84 & 42.0 \\
Islam & & \\
Ethnicity & 157 & 78.5 \\
Yoruba & 39 & 19.5 \\
lgbo & 4 & 2.0 \\
Others (eg, Edo) & &
\end{tabular}

Almost half of the patients, 94 (47.0\%), had bilateral mature cataract; 111 (55.5\%) had their left eyes operated. The preoperative intraocular pressure in most patients, 164 $(82.0 \%)$, was within the normal range in both the operated and unoperated eyes.

The mean baseline CCT of patients a day before surgery in the operated eye was $520.6 \pm 20.3 \mu \mathrm{m}$. This increased by $76.9 \mu \mathrm{m}(597.9 \pm 30.4 \mu \mathrm{m})$ a day after surgery. By 2 weeks, the mean CCT reduced to $555.2 \pm 24.7 \mu \mathrm{m}$, and at 12 weeks, it was $525.1 \pm 19.7 \mu \mathrm{m}$. These differences were found to be statistically significant $(P<0.05)$ (Table 2$)$. The mean CCT, however, reduced closest to the preoperative value with a mean of $525.1 \pm 19.5 \mu \mathrm{m}$ at 8 weeks after surgery was performed (Figure 1).

The mean baseline CCT of patients a day before surgery in the unoperated eye was $521.0 \pm 19.7 \mu \mathrm{m}$; this increased by $6.6 \mu \mathrm{m}(529.5 \pm 21.3 \mu \mathrm{m})$ a day after surgery, and by 2 weeks, it has reduced to $524.9 \pm 21.4 \mu \mathrm{m}$. These differences were found to be statistically significant $(P<0.05)$ (Table 3$)$.
At 4 weeks, the mean CCT $(522.7 \mu \mathrm{m})$ was closest to the preoperative value, while at 12 weeks, the mean CCT was $523.1 \pm 20.3 \mu \mathrm{m}$ (Figure 1).

\section{Discussion}

Most of the patients were elderly, reemphasizing the aging process as the commonest etiology of uncomplicated cataract in the study population. There were more males in this study pointing to the fact that women still have poor access to eye health services often with their influencing factors such as economic, geographic, cultural, social, and sex issues as reported by Mganaga et al. ${ }^{8}$ The largest proportion are Yorubas, and this is not unconnected with the location of study center in the south-western part of Nigeria where the predominant ethnic group is the Yorubas.

Bilateral mature cataracts being the commonest in this finding showed the burden of binocular-blinding cataracts in this population. The mean preoperative $\mathrm{CCT}$ in the operated eye (CCTo) was similar to those documented by Bolz et $\mathrm{al}^{9}$ but in contrast to the findings of Salvi et al and Ventura et al. ${ }^{10,11}$ This difference could have been due to the type of instrument used in measurements of corneal thickness. Several investigations had shown a consistent overestimation of corneal thickness with optical systems compared with ultrasound measurements. ${ }^{12}$ However, reported measurements of CCT determined by ultrasonic pachymetry exhibited greater fluctuations than those estimated by optical low-coherence reflectometry pachymetry. ${ }^{11}$ Moreover, these contrasting studies were done in the Euroid population with relatively thicker corneas compared to the predominantly Negroid population of Native Africans in this study. ${ }^{13}$

Cataract surgery induced an increase in mean corneal thickness on the first day; this is in contrast to Salvi et a ${ }^{10}$ study done in the white population. However, this increase was reduced at 2 weeks with a further decrease till eighth week. This study showed that the difference in corneal thickness between pre- and postoperative values in the operated eye

Table 2 Mean difference in central corneal thickness in operated eye at various times in relation to central corneal thickness before surgery

\begin{tabular}{|c|c|c|c|c|}
\hline Mean CCTo time & Mean CCTo & CCTo (day 0-various time sets) & $P$-value* & Confidence interval (95\%) \\
\hline Day 0 & $520.6 \pm 20.3$ & & & \\
\hline Day I & $597.9 \pm 30.4$ & -76.9 & 0.000 & -80.34 to -73.47 \\
\hline 2 weeks & $555.2 \pm 24.7$ & -34.3 & 0.000 & -36.56 to -31.88 \\
\hline 4 weeks & $533.7 \pm 19.4$ & -12.7 & 0.000 & -14.10 to -11.29 \\
\hline 8 weeks & $525.1 \pm 19.5$ & -4.1 & 0.000 & -4.76 to -3.48 \\
\hline 12 weeks & $525.1 \pm 19.7$ & -4.1 & 0.000 & -4.62 to -3.54 \\
\hline
\end{tabular}

Notes: Various time sets: day I, 2 weeks, 4 weeks, 8 weeks, and 12 weeks after surgery. *Paired $t$-test. Abbreviation: CCTo, central corneal thickness in operated eye. 


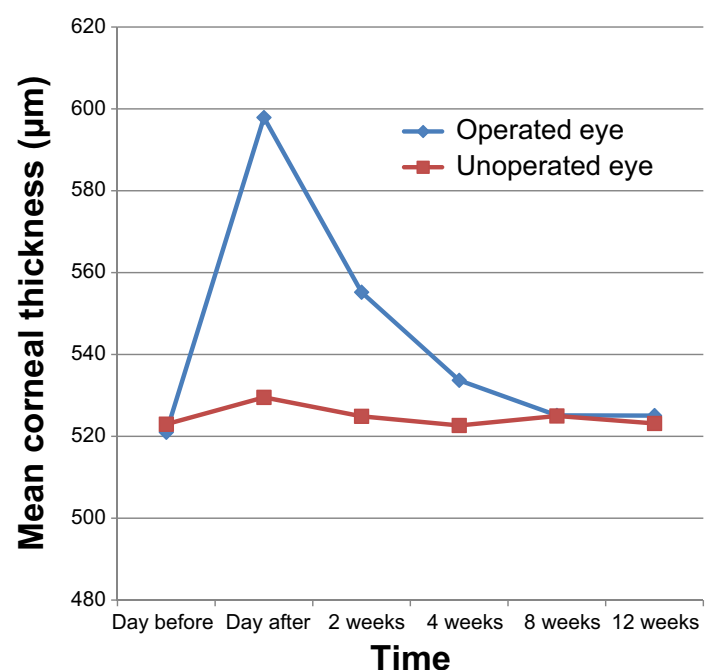

Figure I Length of time it takes for the cornea to return to preoperative thickness value.

Notes: The mean corneal thickness in the operated eye before surgery was $520.6 \pm 20.3 \mu \mathrm{m}$. This rose to $597.9 \pm 30.4 \mu \mathrm{m}$ a day after surgery but reduced relatively 2 weeks after surgery to $555.2 \pm 24.7 \mu \mathrm{m}$. The mean central corneal thickness, however, reduced closest to the preoperative value with a mean of $525.1 \pm 19.5 \mu \mathrm{m}$ at 8 weeks after surgery was performed. In the unoperated eye, the mean corneal thickness before surgery was $521.0 \pm 19.7 \mu \mathrm{m}$. This rose to the highest a day after surgery with mean of $529.5 \pm 21.3 \mu \mathrm{m}$ and reduced close to its preoperative thickness value at 4 weeks post-surgery with mean of $522.7 \pm 21.4 \mu \mathrm{m}$.

was statistically significant. This is in agreement with Jacob's study ${ }^{14}$ that reported that maximal increase occurred within 24 hours following cataract surgery. Also, the study showed similarity with Bolz et al, ${ }^{9}$ Ventura et al, ${ }^{11}$ and Cheng et al ${ }^{15}$ studies where increase followed by gradual decreases in corneal thickness was recorded following cataract surgery.

Interestingly, there was a change in the corneal thickness value post-cataract surgery in the unoperated eye by an increase of $1.26 \%$ on day 1 followed by reduction at 2 weeks. A slight increase was then recorded again at 8 weeks with subsequent reduction by 12 weeks. This study showed a statistical significance in the difference in corneal thickness between pre- and postoperative values up to 2 weeks in the unoperated eye. This is in contrast with Salvi et $\mathrm{al}^{10}$ study where there was just a very small insignificant difference from preoperative values.
The mechanism of increases in the corneal thickness value in the unoperated eye as found in this study is unclear, since no surgery which could pose a risk to the eye was performed on these eyes. It is also not unlikely to consider sympathetic response as the mechanism. However, it has been postulated that once the body is exposed to injury or trauma, all body cells become sensitized by the inflammatory mediators which are system and tissue specific, such that a fresh insult to any parts of the body stimulates an exaggerated inflammatory response in that affected area as demonstrated in an animal model.${ }^{16}$ It is noteworthy that El-Hirazi et al ${ }^{17}$ described a similar consensual inflammation of unknown etiology following ocular surgery in the unoperated eye attributable to phacoemulsification and trabeculectomy in the consensual eye using Kowa laser flare meter and laser cell counter. The amount of inflammation in the nonoperated eyes of 60 patients studied returned to the preoperative levels by day 28 . Similarly, Table 3 shows the return of the CCT to the preoperative state occurring between the second week and fourth week in this study. There is no gain saying the plausible roles of an exaggerated inflammatory response in this phenomenon following controlled trauma in the contralateral eye, and more studies will be needed to explain the etiopathogenesis of this unexplained transient CCT changes.

In this study, it was found that the mean CCT in the operated eye returned closest to the preoperative values by eighth week postoperatively and remained same till 12 weeks. This is not in agreement with the study done by Jacob, ${ }^{14}$ which reported attainment of preoperative value by 4 weeks (28 days); this wide disparity may be due to the phacoemulsification technique used here, which is different from the technique used in this study. However, this study may be similar to Ventura et al study, in which there was restoration of preoperative thickness value by 3 months. ${ }^{11}$ This study could not be compared to Olsen and Eriksen study ${ }^{18}$ and Kohlhaas et al study ${ }^{19}$ where preoperative corneal thickness values were reached by 6 months and 12 months, respectively, as our study patients were only followed up for 3 months. The limitations

Table 3 Mean difference in central corneal thickness in unoperated eye at various times in relation to central corneal thickness before surgery

\begin{tabular}{lllll}
\hline Mean CCTu time & Mean CCTu & CCTo (day 0-various time sets) & P-value* & Confidence interval (95\%) \\
\hline Day before surgery & $521.0 \pm 19.7$ & & & -7.53 to -5.60 \\
Day after surgery & $529.5 \pm 21.3$ & -6.6 & 0.000 & -2.63 to -1.25 \\
2 weeks & $524.9 \pm 21.4$ & -1.9 & 0.000 & -0.19 to 0.78 \\
4 weeks & $522.7 \pm 20.0$ & 0.3 & 0.234 & -3.96 to -0.06 \\
8 weeks & $525.0 \pm 22.7$ & -2.0 & 0.143 & -0.48 to 0.12 \\
\hline I weeks & $523.1 \pm 20.3$ & -0.2 & 0.230 & \\
\hline
\end{tabular}

Notes: Various time sets: day I, 2 weeks, 4 weeks, 8 weeks, and 12 weeks after surgery. *Paired $t$-test.

Abbreviations: CCTu, central corneal thickness in unoperated eye; CCTo, central corneal thickness in operated eye. 
of study are the time constraints, which do not allow prolonged follow-up as a basis for comparison of findings with other similar studies that had longer study follow-up duration, the lack of correlation of endothelial cell counts using specular microscopy with CCT measured by ultrasound pachymetry, and nonavailability of balanced salt solution for anterior chamber irrigation and aspiration for this study.

\section{Conclusion and recommendation}

This study revealed that there was a transient increase in corneal thickness following cataract surgery with subsequent progressive decrease as the postoperative day progresses till 12th week. Overall, it took 8 weeks for the corneal thickness in the operated eye to return closest to its preoperative value. The unoperated eye also showed a transient increase in corneal thickness, which was found to be statistically significant till the fourth week.

It is therefore recommended that conscious and adequate measures should be taken to reduce manipulation on the cornea during cataract surgery in order to achieve relatively reduced CCT and endothelial cell loss with immediate postoperative patient's satisfaction, and to improve patient's vision and quality of life. A further research on the possibility of increasing postoperative CCT in an unoperated eye as found in this study following surgery in the contralateral eye can be explored with a view to unraveling the mechanism behind it.

Postoperative refraction may be delayed until eighth week after manual SICS in view of the recovery time for the CCT to return to its preoperative values in this study. Earlier refraction at 4 weeks may not be stable and reproducible following this procedure in our patients.

\section{Disclosure}

The authors have no proprietary or commercial interest in any materials discussed in this article.

\section{References}

1. WHO. WHO fact sheet 2012. 2012. Available from: www.who.int/ mediacentre/factsheets/fs282/en/. Accessed August 1, 2014.

2. WHO. Prevention of blindness and visual impairment. 2014. Available from: http://www.who.int/blindness/causes/priority/en/index1.html. Accessed October 7, 2014.

Clinical Ophthalmology

\section{Publish your work in this journal}

Clinical Ophthalmology is an international, peer-reviewed journal covering all subspecialties within ophthalmology. Key topics include: Optometry; Visual science; Pharmacology and drug therapy in eye diseases; Basic Sciences; Primary and Secondary eye care; Patient Safety and Quality of Care Improvements. This journal is indexed on
3. National blindness survey. 2014. Available from: http://pbunion.org/ Countriessurveyresults/Nigeria/Nigeria_survey_Summary_report.pdf. Accessed October 7, 2014.

4. Portellinha W, Belfort R Jr. Central and peripheral corneal thickness in newborns. Acta Ophthalmol. 1991;69:247-250.

5. Schlesselman JJ. Sample size requirements in cohort and case control studies of disease. Am J Epid. 1974;99(6):381-384.

6. Venkatesh R, Muralikrishnan R, Balent LC, Prakash SK, Prajna NV. Outcomes of high volume cataract surgeries in a developing country. Br J Ophthalmol. 2005;89:1079-1083.

7. Venkatesh R, Tan CSH, Singh GP, Veena K, Krishna KT, Ravindran RD. Safety and efficacy of manual small incision cataract surgery for brunescent and black cataracts. Eye. 2009;23:1155-1157.

8. Mganaga $\mathrm{H}$, Lewallen S, Courtright P. Overcoming gender inequity in prevention of blindness and visual impairment in Africa. Middle East African. J Ophthalmol. 2011;18(2):98-101.

9. Bolz M, Sacu S, Drexler W, Findl O. Local corneal thickness changes after small-incision cataract surgery. J Cataract Refract Surg. 2006;32(10):1667-1671.

10. Salvi SM, Soong TK, Kumar BV, Hawksworth NR. Central corneal thickness changes after phacoemulsification cataract surgery. J Cataract Refract Surg. 2007;33(8):1426-1428.

11. Ventura ACS, Wälti R, Böhnke M. Corneal thickness and endothelial density before and after cataract surgery. Br J Ophthalmol. 2001;85:18-20.

12. Gonzalez-Meijome JM, Cervino A, Yebra-Pimentel E, Parafita MA. Central and peripheral corneal thickness measurement with Orbscan II and topographical ultrasound pachymetry. J Cataract Refract Surg. 2003;29:125-132.

13. Nangia V, Jonas JB, Sinha A, Matin A, Kulkarni M. Central corneal thickness and its association with ocular and general parameters in Indians: the central India eye and medical study. Ophthalmology. 2010;117(4):705-710.

14. Jacob JS. Corneal thickness changes following cataract surgery: effect of lens implantation and sodium hyaluronate. Br J Ophthalmol. 1985;69(8):567-571.

15. Cheng H, Bates AK, Wood L. Positive correlation of corneal thickness and endothelial cell loss. Arch Ophthalmol. 1988;106:920-922.

16. Xu H, Chen M, Forrester JV, Lois N. Cataract surgery induces retinal pro-inflammatory gene expression and protein secretion. Invest Ophthalmol Vis Sci. 2011;52(1):249-255.

17. El-Hirazi SM, Feldman RM, Ruiz RS, Villanueva G, Chuang AZ. Consensual inflammation following ocular surgery. Ophthalmic Surg Lasers. 1999;30(4):254-259.

18. Olsen T, Eriksen JS. Corneal thickness and endothelial damage after intraocular lens implantation. Acta Ophthalmol. 1980;58:773-786.

19. Kohlhaas M, Stahlhut O, Tholuck J. Changes in corneal thickness and endothelial cell density after cataract extraction using phacoemulsification. Ophthalmologe. 1997;94:515-518.

\section{Dovepress}

PubMed Central and CAS, and is the official journal of The Society of Clinical Ophthalmology (SCO). The manuscript management system is completely online and includes a very quick and fair peer-review system, which is all easy to use. Visit http://www.dovepress.com/ testimonials.php to read real quotes from published authors. 